\title{
Spatiotemporal Changes and Simulation of the Architectural Ethnicity at World Heritage Sites under Tourism Development
}

\author{
Xi Yang, ${ }^{1}$ Cong Peng $\mathbb{D}^{2},{ }^{2}$ Xueling Jiang, ${ }^{2}$ Juan Wang, ${ }^{2}$ and Jun Liu $\mathbb{D}^{2}$ \\ ${ }^{1}$ Yinxing Hospitality Management College of CUIT, Chengdu, China \\ ${ }^{2}$ Tourism School, Sichuan University, Chengdu, Sichuan 610065, China \\ Correspondence should be addressed to Jun Liu; liujun_igsnrr@126.com
}

Received 26 February 2020; Revised 20 April 2020; Accepted 30 April 2020; Published 20 May 2020

Guest Editor: Jianhong (Cecilia) Xia

Copyright $(02020$ Xi Yang et al. This is an open access article distributed under the Creative Commons Attribution License, which permits unrestricted use, distribution, and reproduction in any medium, provided the original work is properly cited.

\begin{abstract}
This study was the first to integrate the quantitative analysis and simulation of spatiotemporal processes into research on the ethnicity of tourist destinations. Selecting the world heritage site of Jiuzhaigou in China as a case study, we employed remote sensing images and field observation to obtain the spatial distribution data of the site's architectural ethnicity of 2005 and 2015. Logistic regression analysis was used to determine the mechanism driving changes in architectural ethnicity. Then, we proposed a Logistic-CA-Markov coupling model to analyse architectural ethnicity transformations and simulate the spatiotemporal patterns of the ethnicity of architecture at the site in 2025 and 2035. It was found that from 2005 to 2015, the overall architectural ethnicity at the heritage site trended downwards and displayed an uneven spatial distribution: weak ethnicity in the west and strong in the east. A tight relationship was found between the ethnicity of heritage architecture and the level of tourism development although the ethnicity of tourism architecture was weaker than that of nontourism architecture, and the ethnicity of tourism architecture was continuously strengthening. Factors affecting spatial changes in architectural ethnicity mainly included altitude, slope, distance from main transport lands and waters, and the original type of ethnicity. It is expected that, from 2015 to 2035 , the overall architectural ethnicity in Jiuzhaigou will increase.
\end{abstract}

\section{Introduction}

With the rapid urbanization of developing countries, the cultural landscapes of many regions, meaning the local traditions, ethnic groups, and architecture of those regions, are facing the threat of disintegration, transmutation, or even perishing [1-5]. In the last decade or so, China has experienced the most drastic urbanization, with an increase from $42.99 \%$ in 2005 to $58.52 \%$ in 2017 ; in real terms, this meant that approximately 300 million people moved from farms to cities, and approximately 7000 traditional villages vanished $[6,7]$. As a result, the protection of humanistic landscapes and architectural diversity against the impacts of urbanization has gradually come to the fore as an important field in sustainable research $[8,9]$.

In underdeveloped countries, tourism is an important impetus for urbanization [10]. This is particularly apparent in certain world heritage sites with a fragile biophysical environment and congregations of ethnic minorities. The distinctive life habits, production methods, architecture, costumes, and other cultural aspects of ethnic minorities make these Chinese heritage sites unique tourist attractions and render them internationally renowned as tourist destinations. In 2016 alone, the world natural heritage site of Huanglong, China, attracted approximately 2.35 million visitors in total, which accounted for ticket revenue of 63.03 million USD; another world natural heritage site, Heavenly Lake in the Tianshan Mountains in Xinjiang, attracted approximately 2.09 million visitors and generated a revenue of 225.56 million USD. In the world heritage site of Jiuzhaigou, the tourism industry has become a major pillar of the local economy and promotes the local urbanization; its development inevitably changes the local architecture, which is the main carrier of ethnicity $[11,12]$. Such a change would significantly affect the protection of humanistic landscapes and architectural diversity of the site. 
To promote the sustainable development of world heritage sites, it is important to perceive and understand the spatiotemporal transformation of the architectural ethnicity of heritage sites with rapid tourism development and settlements of ethnic minorities. The main objectives of this study were to analyse the architectural ethnicity transformations, determine the mechanisms driving such changes, and simulate the future changes in architectural ethnicity in Jiuzhaigou. In this way, the architecture of heritage attractions may be optimized and ethnicity may be safeguarded against the risk of disappearance due to rapid tourism development. This study could provide a reference for government decision-making and the management of heritage sites.

\section{Literature Review}

Tourism industry changes the local architecture, which reflects the influence of tourism industry on the local culture [13]. There has been studies on the impact of tourism development on architecture from different perspectives, but our understanding of its impact on architectural ethnicity is inadequate [14-16]. In world heritage sites, tourism development has given rise to questions about the protection of humanistic landscapes and architectural diversity. Existing studies on the impacts and effects of tourism development on ethnicity have largely focused on perception [17-19]. For instance, in his study of ethnic tourism in Lugu Lake in Yunnan province, Yang examined tourists' perception and revealed that many tourists were not only concerned about cultural changes and the diminishing of traditional customs but also believed that maintaining cultural authenticity and integrity was fundamental to the sustainable development of ethnic tourism [20]. Using two tourist areas in Iran, Sare'in and Masooleh, as examples, Zamani-Farahani et al. incorporated residents' perceptions in their research on the sociocultural impacts of tourism and concluded that tourism had positive sociocultural influences [21]. However, few studies have explored the process and patterns of the spatiotemporal transformation of ethnicity. The obstacle to these studies is the difficulty in identifying the attributes of each cultural space based directly on remote sensing images; to establish a reliable database with a longer time series and different types of data, it requires case-by-case investigations. Hence, for research on changes in the ethnicity of tourist destinations, using the physical indicator of ethnicity, architecture, to analyse the spatial changes in ethnicity and to reveal the possible influence of tourism development on ethnicity is a new direction that is worth exploring.

Crystallizing the process of the spatial transformation of ethnicity and identifying the mechanism driving such transformation to illustrate its pattern of spatiotemporal variation is the key to current studies on the ethnicity of tourist destinations. As an effective tool for the identification and quantitative analysis of driving factors, the logistics model has been widely applied to studies on the relationship between the spatiotemporal changes of land use in countries or regions such as China, Portugal, and India and the driving factors behind these changes [22-27]. Therefore, applying this model to the analysis of the mechanism driving the spatial changes in ethnicity will yield a higher level of reliability.

Dynamic simulation of the spatial changes in ethnicity will be the key to guiding the ethnicity protection of tourist areas in the future; safeguarding their ethnicity will be of great significance to the sustainable development of these tourist destinations. Currently, the application of the CAMarkov model is relatively widespread [28, 29]. In China, He et al. adopted this model to simulate the spatial changes of land use in the Lake Dianchi watershed in 2017 and 2026, respectively; in other countries, Jenerette et al. and Guan et al. applied this model to forecast the land use changes in central Arizona, Phoenix region and Saga, and Japan from 2015 to 2042, respectively [30-32]. Thus, the current focus of ethnicity research rests on the application of the CA-Markov model to the simulation and prediction of spatial patterns of ethnicity and the improvement of simulation accuracy.

\section{Research Regions}

The World heritage site of Jiuzhaigou is located in Zhangzha Town, Jiuzhaigou County, Ngawa Tibetan and Qiang Autonomous Prefecture of Sichuan Province (Figure 1), with the geographic coordinates of longitude $100^{\circ} 30^{\prime}-104^{\circ} 27^{\prime}$ and latitude $30^{\circ} 35^{\prime}-34^{\circ} 19^{\prime}$. Jiuzhaigou was officially opened to tourist visits in 1984 and was thereafter inscribed on the UNESCO World Natural Heritage List. In 2007, it was classified as a $5 \mathrm{~A}$ scenic area by the China National Tourism Administration (the highest ranking for scenic areas in China). Jiuzhaigou is renowned for its "six beauties", its green lakes, banked waterfalls, snowy peaks, colourful forests, Tibetan culture, and blue ice, which attract crowds of Chinese and foreign tourists every year. The annual number of visitors increased from 1.91 million in 2005 to 5.09 million in 2015, as tourism has become the pillar industry of the heritage site.

Jiuzhaigou is named after its nine Tibetan villages, including Zechawa, Shuzheng, and Zharu, where Tibetan architecture, traditional costumes, cultural customs, and other humanistic elements with strong ethnic characteristics comprise the major appeals to tourists. With the advancement of the tourism industry, the core of the humanistic landscape, community architecture, and its spatial patterns undergo consistent changes. Traditionally, Tibetan architecture mainly comprised column-and-tie wooden structures built with local materials; the main structures usually consisted of three layers: the first floor was for herding livestock, the second was for residential use, and the top level was for storing grains and other household materials. However, the architectural structure and spatial functions of these buildings have undergone radical changes due to improvements in architectural techniques and the requirements of tourism businesses (Figure 2). Therefore, to investigate the spatial changes in the ethnicity of Tibetan architecture, this study selected five Jiuzhaigou villages as its research targets, Pengfeng, Zhangzha, and Longkang, which are key tourism communities that have been immensely influenced by tourism development, and Congya and Yazha, which have been pushing forward the development of local hostels in recent years. 


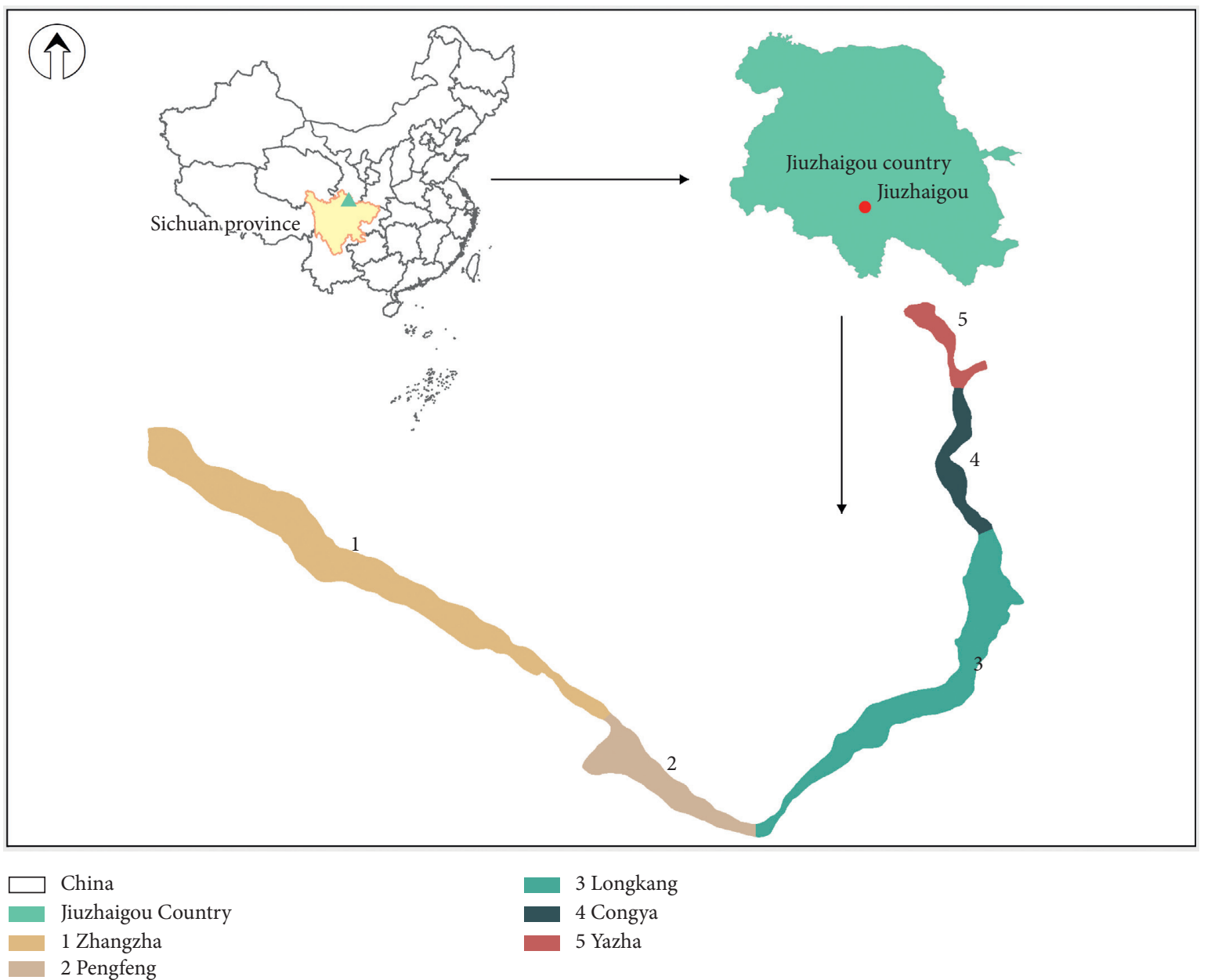

Figure 1: Geographical location of Jiuzhaigou (source: created by the authors on the basis of digital administrative map of China and Sichuan Province from the Resource and Environment Data Cloud Planform (http://www.resdc.cn/) and digital administrative map of research region from the Administrative Department of Jiuzhaigou).

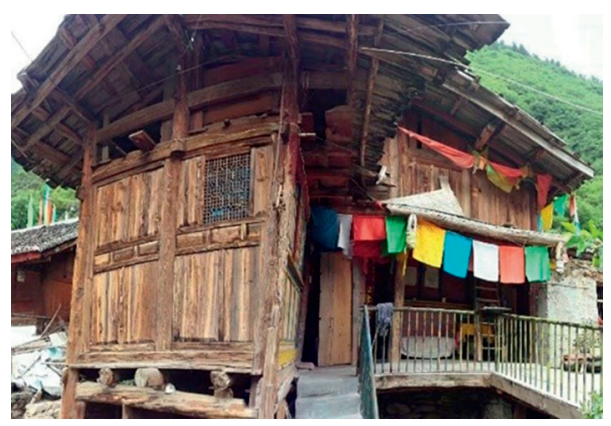

(a)

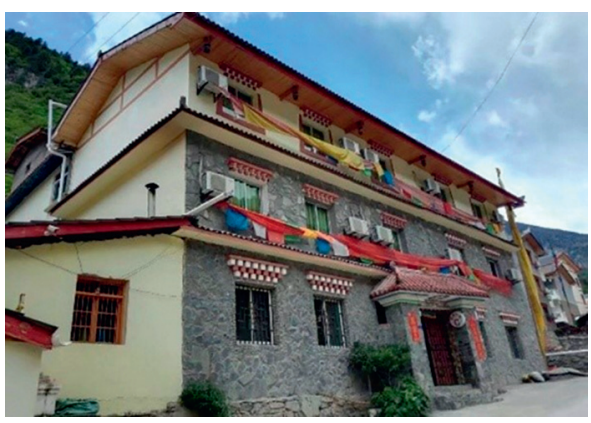

(b)

Figure 2: Comparison of architectural changes in the world heritage site of Jiuzhaigou for the (a) strong ethnicity and (b) weak ethnicity (source: photographed by the authors).

\section{Research Methods and Data}

\subsection{Research Methods}

4.1.1. Construction of Ethnicity Assessment Index System. With reference to past research on settlement landscape, architectural ethnicity, and traditional residential houses, as well as the actual conditions of the research region, this study constructed a hierarchical model (Figure 3) to assess the ethnicity of architecture at the objective, criterion, and index levels, based on suggestions from experts in related research fields such as tourism, architecture, and ethnic minorities, and the guiding principles of integrity, hierarchy, relevance, and predictability [33-39]. The constructed index system 


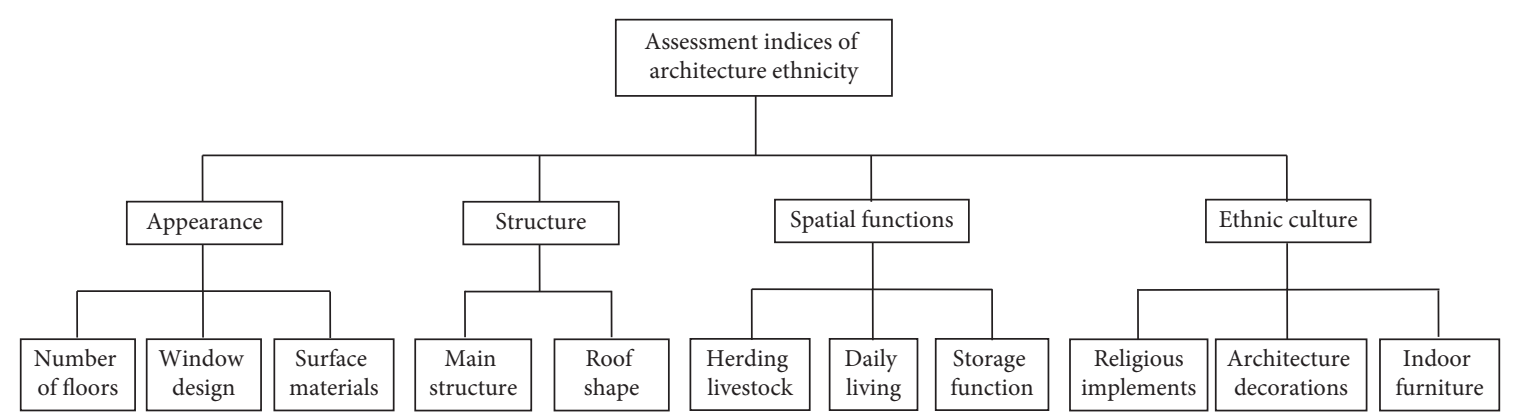

FIgURE 3: Assessment index system for architectural ethnicity at the Jiuzhaigou world heritage site.

encompassed four criteria and 11 indices. It is worth noting that the index of "storage" referred to the specific functions of the top floor for air-drying and storing fodder and stacking household items; this differed from the storage room involved in the "daily living" index.

To quantify the intensity of the ethnicity that each index stands for, this study integrated existing academic papers and suggestions from experts in related research fields to establish a 5-level classification standard: 1 denoted the weakest ethnicity, and 5 the strongest [40-44]. As it was more difficult to classify certain qualitative, descriptive indices into 5 levels, they were sorted into 2,3 , or 4 levels based on the actual conditions. The detailed classification standard was as follows: indices that could only be classified into four levels were assigned scores from 2 to 5 , and 1 was excluded; those that could only be classified into three levels were given the scores of 1,3 , or 5 ; those that could only be classified into two levels were given a score of either 1 or 5 (Table 1) [40-44].

4.1.2. The Analytic Hierarchy Process. The analytic hierarchy process (AHP) is an effective decision-making method for achieving a complex overall goal involving multiple value orientations and a lack of accurate quantitative data, as well as a set of interrelated and mutually restrictive factors. It is widely applied to the analysis and judgement of social, political, and economic issues and is commonly used by Chinese and foreign scholars as a subjective value assignment method [45-47].

With the aid of AHP and the supplementary software Yaahp, the weight of each assessment index of architectural ethnicity was computed. The detailed calculation steps were as follows. (1) A hierarchical model was built (Figure 3). (2) Judgement matrices were constructed: an expert opinion questionnaire was devised based on the hierarchical model; 16 experts in related research fields such as tourism, architecture, and ethnic minority culture from higher education institutions and research institutes, including the Chinese Academy of Sciences, Tongji University, Sun Yatsen University, and Sichuan University, were invited to complete the questionnaire (as Yong et al. pointed out, a group of 15-20 experts usually suffices to make professional academic judgements) [48]. The relative importance of each index in the hierarchy was determined using a scaling method (as shown in Table 2), after which the results of experts' judgement were input into Yaahp for constructing judgement matrices [49]. (3) The consistency ratio was tested: the condition for passing the consistency test was CR $<0.10$. The first round of investigation showed that six experts' judgements failed to pass the test, and they were invited to fill in the questionnaire again; in the second round, one expert failed to pass the test, and that expert's questionnaire response was discarded. Eventually, the group decision-making data obtained from 15 experts were retained. (4) The set of values collected from the experts was analysed statistically: using Yaahp, the mean values of the computational results of the experts' judgement matrices (priorities and weights) were calculated to obtain the weight of each index, as shown in Table 3.

4.1.3. Multifactor Synthetic Evaluation Model. Multifactor synthetic evaluation is the calculation of the aggregate score of each individual structure based on the weighted sums for examining the ethnicity of regional architecture. Its equation is

$$
L=\sum_{i=1}^{n} W_{i} S_{i}
$$

In this equation, $L$ denotes the total ethnicity score of the $i$ th architecture; $i$ indicates the sequence number of the assessment index; $n$ denotes the total number of assessment indices ( $n=11$ in this study); $W_{i}$ represents the weight of the $i$ th index, and $S_{i}$ the score of that architecture in terms of the $i$ th index.

4.1.4. Logistic Regression Analysis. Logistic regression analysis examines the relationship between different types of ethnicity and the driving factors of their changes using the independent variable as the predictive value to calculate event probability. The formula is as follows:

$$
\log \frac{P_{i}}{1-P_{i}}=\beta_{0}+\beta_{1} X_{1}+\beta_{2} X_{2}+\cdots+\beta_{n} X_{n}
$$

where $P_{i}$ denotes the probability that the ethnicity type $i$ appears in each grid cell; $X_{n}$ represents the driving factor; $\beta_{0}$ is the constant; $\beta_{1}-\beta_{n}$ denotes the relevance between driving factors $X_{1}-X_{n}$ and the ethnicity type $i$ : the larger the value of $\beta$, the greater the relevance. Logistic stepwise regression was used to determine the impacts of the driving factors on each 
TABLE 1: Classification standard for assessment indices of architectural ethnicity (sources: created by the authors on the basis of hierarchical model).

\begin{tabular}{|c|c|c|c|}
\hline Criterion & Index & Classification standard & Score \\
\hline \multirow{13}{*}{ Appearance } & \multirow{5}{*}{ Number of floors } & $2 / 3$ & 5 \\
\hline & & 1 & 4 \\
\hline & & 4 & 3 \\
\hline & & 5 & 2 \\
\hline & & 6 or above & 1 \\
\hline & \multirow{4}{*}{ Window design } & Entirely Tibetan & 5 \\
\hline & & Mainly Tibetan & 4 \\
\hline & & Mainly Chinese & 3 \\
\hline & & Entirely Chinese & 2 \\
\hline & \multirow{4}{*}{ Surface materials } & Equivalent to construction materials (rammed earth/wood/stone) & 5 \\
\hline & & $\geq 1 / 2$ stone or wooden decorations & 4 \\
\hline & & $<1 / 2$ stone or wooden decorations & 3 \\
\hline & & Mainly painted and no stone or wooden decoration & 2 \\
\hline \multirow{8}{*}{ Structure } & \multirow{5}{*}{ Main structure } & Traditional wooden structure & 5 \\
\hline & & Modern wooden structure & 4 \\
\hline & & Brick-and-wood structure & 3 \\
\hline & & Brick-and-concrete construction & 2 \\
\hline & & Reinforced concrete/other structures & 1 \\
\hline & \multirow{3}{*}{ Roof shape } & Pitched roof & 5 \\
\hline & & Combination of pitched roof and other shape(s) & 3 \\
\hline & & Flat roof & 1 \\
\hline \multirow{5}{*}{$\begin{array}{l}\text { Spatial } \\
\text { functions }\end{array}$} & \multirow{2}{*}{ Herding livestock } & Functional & 5 \\
\hline & & Not functional & 1 \\
\hline & Daily living & $\begin{array}{c}\text { Scored according to the presence of main chamber, bedroom, prayer hall, field for drying } \\
\text { crop, and storage }\end{array}$ & $1-5$ \\
\hline & \multirow{2}{*}{ Storage } & Functional & 5 \\
\hline & & Not functional & 1 \\
\hline \multirow{5}{*}{ Ethnic culture } & $\begin{array}{l}\text { Religious } \\
\text { implements }\end{array}$ & $\begin{array}{c}\text { Scored according to the presence of white tower, prayer wheel, wind wheel/prayer flag, and } \\
\text { indoor ritual implements }\end{array}$ & $1-5$ \\
\hline & $\begin{array}{l}\text { Architecture } \\
\text { decorations }\end{array}$ & $\begin{array}{c}\text { Scored according to the presence of decorations of the walls, doors and windows, beams } \\
\text { and columns, eaves, and the interior }\end{array}$ & $1-5$ \\
\hline & \multirow{3}{*}{ Indoor furniture } & Mainly Tibetan & 5 \\
\hline & & Mixture of Tibetan and Chinese & 3 \\
\hline & & Mainly Chinese & 1 \\
\hline
\end{tabular}

TABLe 2: 9-Point scale (sources: [49]).

\begin{tabular}{lc}
\hline Scale & Definition \\
\hline 1 & Factors I and II have equal importance. \\
3 & Factor I is slightly more important than Factor II. \\
7 & Factor I is strongly more important than Factor II. \\
9 & Factor I is significantly more important than Factor II. \\
$2,4,6,8$ & Factor I is absolutely more important than Factor II. \\
Reciprocals of the abovementioned & Contrary to the abovementioned, Factor II is more important than Factor I to different extents. \\
\hline
\end{tabular}

type of ethnicity and, through the quantitative relationship between the two, to select the factors with significant influence on the distribution of ethnicity.

The receiver operating characteristic curve (ROC) was adopted to verify the regression results [50]. Usually, the ROC value ranges between 0.5 and 1 . When $0.5<\mathrm{ROC}<0.7$, the predictive outcomes have a lower level of accuracy, whereas $0.7<$ ROC $<0.9$ means moderate accuracy and ROC $>0.9$ means high accuracy. The closer the ROC value is to 1 , the more effective is the prediction.
4.1.5. The Logistic-CA-Markov Coupling Model. The CAMarkov model facilitates precise mining of information regarding spatiotemporal changes, as it integrates the CA model, which can simulate the spatial changes in complex systems, with the Markov model, which can make predictions based on long time series [51]. The logistic regression model was employed to compute the spatial distribution probability of different types of ethnicity, from which the transition rules of the CA model were derived. Combining the rules with the CA-Markov model gave rise to 
TABLE 3: Weights of assessment indices of architectural ethnicity at the Jiuzhaigou world heritage site (sources: created by the authors on the basis of results of the AHP model).

\begin{tabular}{|c|c|c|c|c|}
\hline Objective & Criterion & Weight of criterion & Index & Weight of index \\
\hline \multirow{11}{*}{ Assessment of the ethnicity of architecture } & \multirow{3}{*}{ Appearance } & \multirow{3}{*}{0.3662} & Number of floors & 0.0652 \\
\hline & & & Window design & 0.1070 \\
\hline & & & Surface materials & 0.1940 \\
\hline & \multirow{2}{*}{ Structure } & \multirow{2}{*}{0.2258} & Main structure & 0.1543 \\
\hline & & & Roof shape & 0.0715 \\
\hline & \multirow{3}{*}{ Spatial functions } & \multirow{3}{*}{0.1592} & Herding livestock & 0.0358 \\
\hline & & & Daily living & 0.1044 \\
\hline & & & Storage & 0.0190 \\
\hline & \multirow{3}{*}{ Ethnic culture } & \multirow{3}{*}{0.2488} & Religious implements & 0.1081 \\
\hline & & & Architecture decorations & 0.0881 \\
\hline & & & Indoor furniture & 0.0526 \\
\hline
\end{tabular}

a Logistic-CA-Markov coupling model for simulating and predicting the spatiotemporal patterns of the ethnicity of architecture at the heritage site in 2025 and 2035.

\subsection{Sources of Data}

4.2.1. Survey Data. From 25 May to 3 June 2017, a survey team of eight researchers conducted a 10-day social research in Zhangzha Town, Jiuzhaigou County. The objective of this investigation was to obtain the ethnicity values of all buildings in the study area of year 2005 and 2015 to analyse the spatiotemporal changes of architectural ethnicity. The tasks undertaken included (1) carrying out field observation of all housing structures, keeping a written record of relevant information, and taking pictures of some of the architecture for photographic information; and (2) through participatory rural appraisal (PRA) [52] and in-depth interviews with town government officials, village-level cadres of each village, business operators in all types of tourism, and parties not involved in tourism, first-hand information and data were obtained regarding the research region, such as its history and the status quo of land use, its course of tourism development, the architectural characteristics at different times in history, its renovation and reconstruction, and the migration of villages.

4.2.2. Spatial Data. Based on a QuickBird image of the research region captured in 2005 (at a resolution of $0.7 \mathrm{~m}$ ) and a Google Earth remote sensing image captured in 2015 (at a resolution of $0.6 \mathrm{~m}$ ), manual visual interpretation was used to examine the different types of land use in the region (Figure 4). Afterwards, the interpretation results were each verified and rectified using the results of the 10-day field survey. ArcGIS software was employed to construct the land use distribution diagrams for 2005 and 2015. Lastly, the rivers, roads, and construction lands were extracted and integrated with the other types of land use to obtain the spatial distribution data of the construction lands in the five villages in Zhangzha Town at two different time periods.

\section{Results and Analysis}

5.1. Spatiotemporal Changes in Architecture Ethnicity at the Heritage Site from 2005 to 2015. From 2005 to 2015, the overall ethnicity of the architecture at the world heritage site trended downwards (Table 4), with the average value dropping from 2.93 in 2005 to 2.53 in 2015. In both 2005 and 2015, architecture with weak (the weakest and weaker) ethnicity took up the largest proportion of the total area (Table 5), 62.61\% and 70.75\%, respectively.

There was a great deal of variance among the spatial patterns of the architectural ethnicity of the villages (Figure 5). Overall, there was an unbalanced structure of weak ethnicity in the west and strong in the east. In 2005, the average value of architectural ethnicity in the western villages, Zhangzha and Pengfeng, was 2.95, lower than 3.13 in the eastern villages, Longkang, Congya, and Yazha. In 2015, the average architectural ethnicity of the western villages was 2.52, significantly lower than 2.81 , which was the average value of the eastern villages.

The architectural ethnicity at the heritage site was closely related to the tourism development of the villages. Villages that were close to the entrance of the scenic area and had developed earlier had weaker ethnicity, while those that were far from the entrance and had developed later displayed stronger ethnicity. From 2005 to 2015, the villages with the strongest or stronger ethnicity were Yazha and Congya, respectively, both of which were further away from the entrance and among the latest to have developed; meanwhile, the weakest ethnicity was attributed to Longkang Village, which was near the entrance and had developed earlier. In 2015, 83.85\% of the architecture in Longkang had weak ethnicity.

Although the ethnicity of tourism architecture was higher than that of nontourism architecture, the two types of architecture demonstrated different trends and changes. The average ethnicity score of the former increased from 2.22 to 2.38, while that of the latter decreased from 3.22 to 2.96 . Over the decade, there were two villages where both tourism and nontourism architecture had increased their ethnicity and three villages where both had weakened their ethnicity.

5.2. Changes in the Constituent Factors of Architectural Ethnicity from 2005 to 2015. All constituting factors of architectural ethnicity trended downwards from 2005 to 2015 (as shown in Table 6 and Figure 6). Of these, "appearance" had the largest decrease in ethnicity, related to the 


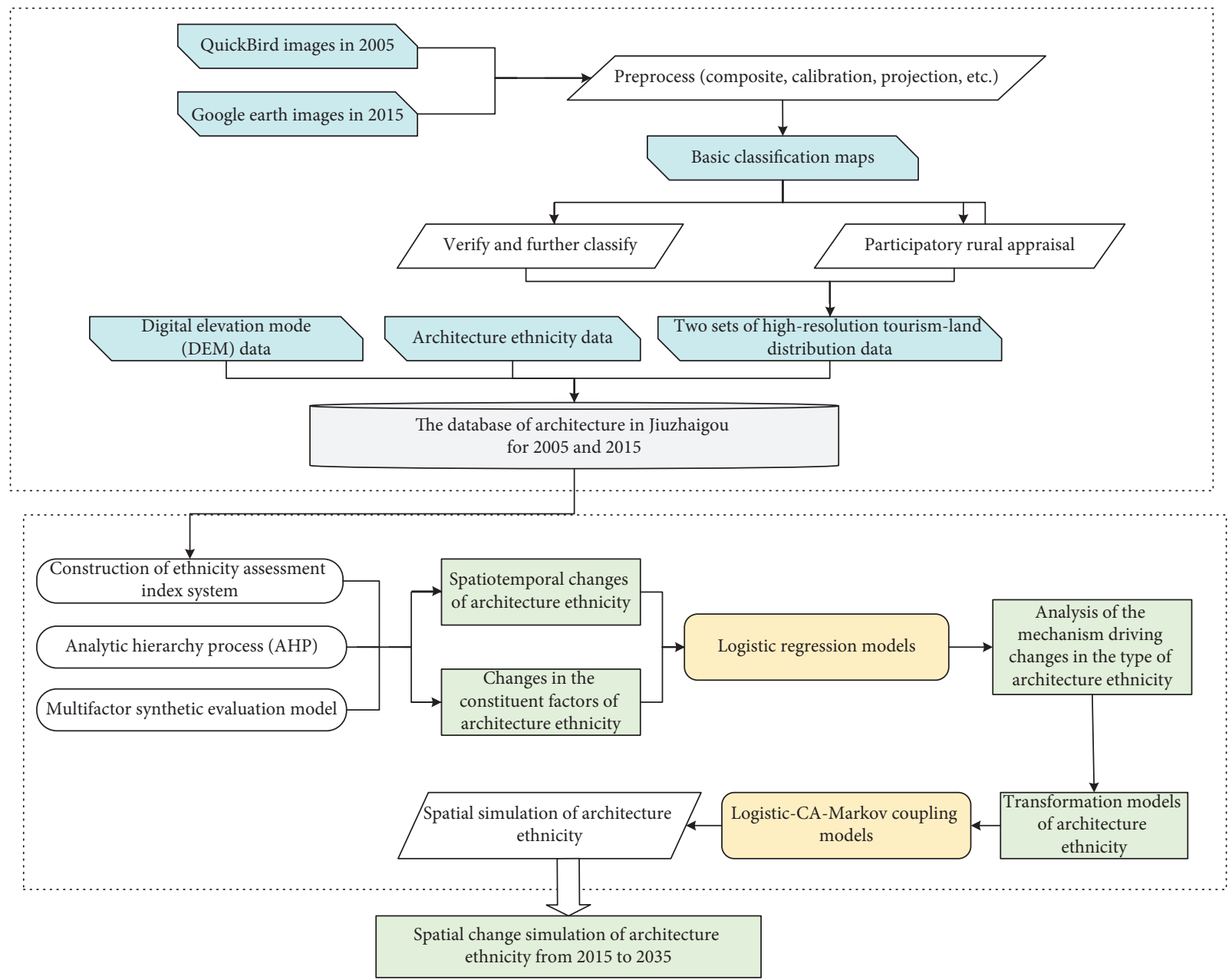

FIGURE 4: Flowchart of methodology adopted for the study.

TABLE 4: Average values of architectural ethnicity in the research region and different villages on the basis of the survey data and spatial data.

\begin{tabular}{ccccc}
\hline Year & Name & Overall average & Average ethnicity of tourism architecture & Average ethnicity of nontourism architecture \\
\hline \multirow{4}{*}{2005} & Research region & 2.93 & 2.22 & 3.22 \\
& Yazha Village & 3.40 & 2.93 & 3.48 \\
Congya Village & 3.30 & 4.25 & 3.29 \\
Longkang Village & 2.70 & 2.14 & 3.10 \\
& Pengfeng Village & 2.95 & 2.56 & 3.34 \\
Zhangzha Village & 2.94 & 2.02 & 3.20 \\
\hline Research region & 2.53 & 2.38 & 3.96 \\
Yazha Village & 3.13 & 2.78 & 3.46 \\
Congya Village & 2.94 & 2.64 & 2.66 \\
Longkang Village & 2.36 & 2.25 & 2.66 \\
Pengfeng Village & 2.49 & 2.46 & 2.88 \\
Zhangzha Village & 2.55 & 2.44 & & \\
\hline
\end{tabular}

substantial use of modern paint in lieu of traditional wood or stone materials to decorate the external walls in the region, leading to a dramatic decrease in the ethnicity of "surface material." The next was the decline of ethnicity caused by changes in "ethnic culture," mainly resulting from the substitution of Tibetan furniture with Chinese-style furniture. In addition, since the implementation of the "Returning Farmland to Forest" program in Jiuzhaigou in 1999, immense effort had been put into developing the tourism industry. As the residents at the heritage site had improved their material conditions and actively adapted to the modern lifestyle, the function of herding livestock faded away, and the storage function of residences diminished. Instead, the spatial functions of the bottom and top levels had largely been turned to commercial purposes.

Tourism development promoted the preservation and elevation of architectural ethnicity. As tourism architecture focused more on the conservation and continuation of the 
TABLE 5: Composition of ethnicity type of architecture in different villages from 2005-2015 (sources: created by the authors on the basis of the survey data and spatial data).

\begin{tabular}{|c|c|c|c|c|c|c|}
\hline Year & Name & Weakest (\%) & Weaker (\%) & Medium (\%) & Stronger (\%) & Strongest (\%) \\
\hline \multirow{6}{*}{2005} & Research region & 36.24 & 26.36 & 8.61 & 12.85 & 12.24 \\
\hline & Yazha Village & 0.97 & 21.98 & 1.93 & 33.82 & 41.30 \\
\hline & Congya Village & 15.96 & 5.21 & 10.42 & 16.94 & 51.47 \\
\hline & Longkang Village & 44.10 & 26.67 & 11.32 & 10.59 & 7.32 \\
\hline & Pengfeng Village & 13.73 & 27.61 & 10.28 & 34.44 & 13.94 \\
\hline & Zhangzha Village & 39.24 & 27.20 & 6.70 & 14.26 & 12.60 \\
\hline \multirow{6}{*}{2015} & Research region & 39.02 & 31.73 & 12.85 & 12.24 & 4.16 \\
\hline & Yazha Village & 8.10 & 17.85 & 17.44 & 33.03 & 23.59 \\
\hline & Congya Village & 12.15 & 30.45 & 19.25 & 22.86 & 15.28 \\
\hline & Longkang Village & 47.97 & 35.88 & 7.39 & 7.08 & 1.68 \\
\hline & Pengfeng Village & 24.75 & 40.13 & 14.20 & 20.92 & 0.00 \\
\hline & Zhangzha Village & 43.45 & 28.88 & 14.62 & 9.71 & 3.34 \\
\hline
\end{tabular}

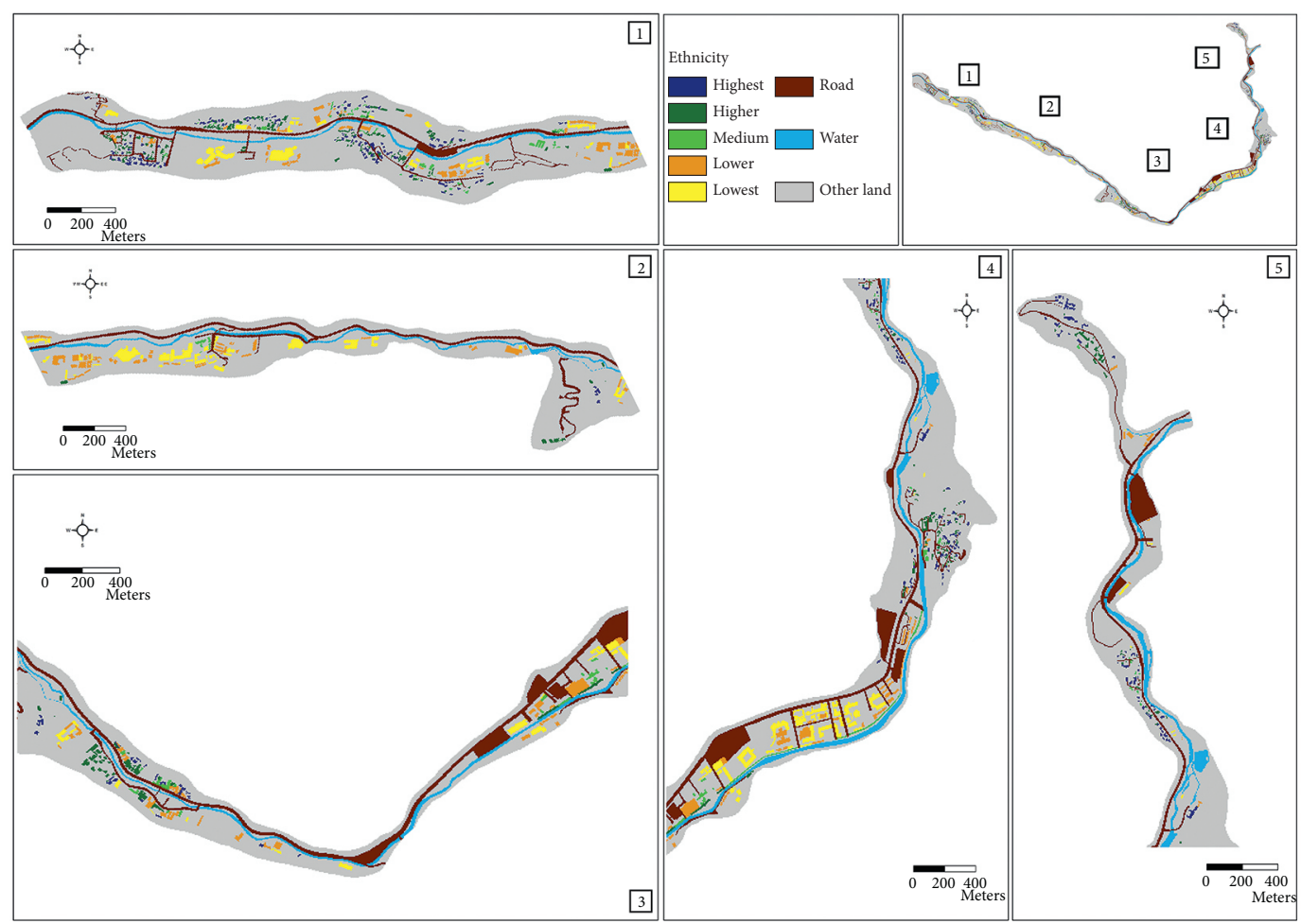

(a)

Figure 5: Continued. 


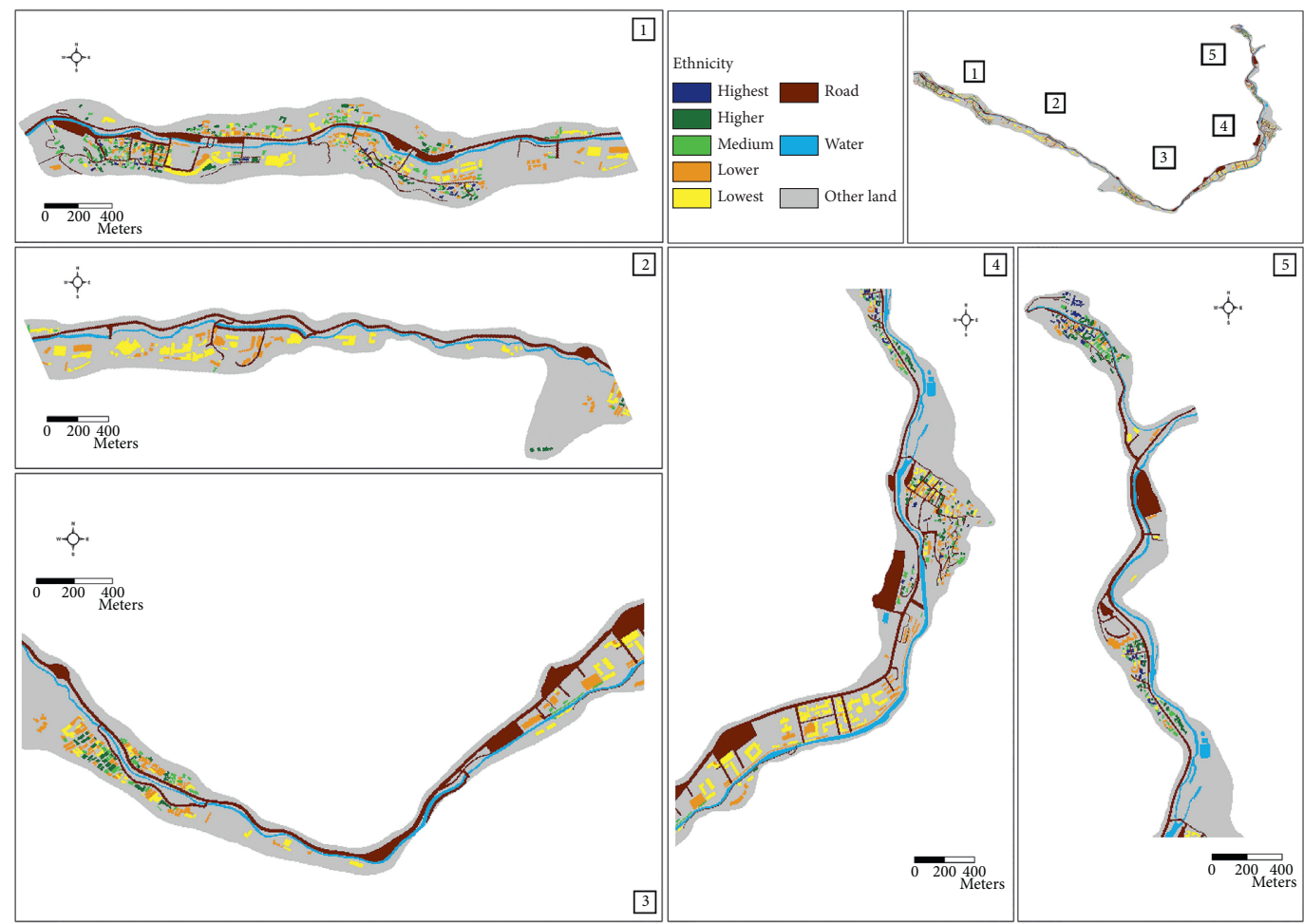

(b)

FIGURE 5: Ethnicity type distribution of architecture in Jiuzhaigou for (a) 2005 and (b) 2015.

TABLE 6: Average scores of factors constituting architectural ethnicity from 2005 to 2015 (sources: created by the authors on the basis of the survey data and spatial data).

\begin{tabular}{|c|c|c|c|c|c|c|c|c|c|}
\hline \multirow{3}{*}{ Criterion } & \multicolumn{4}{|c|}{ Score of criterion } & \multirow{3}{*}{ Index } & \multicolumn{4}{|c|}{ Score of index } \\
\hline & \multicolumn{2}{|c|}{ Total } & \multicolumn{2}{|c|}{$\begin{array}{c}\text { Tourism } \\
\text { architecture }\end{array}$} & & \multicolumn{2}{|c|}{ Total } & \multicolumn{2}{|c|}{$\begin{array}{c}\text { Tourism } \\
\text { architecture }\end{array}$} \\
\hline & 2005 & 2015 & 2005 & 2015 & & 2005 & 2015 & 2005 & 2015 \\
\hline Appearance & 1.25 & 1.10 & 1.05 & 1.08 & $\begin{array}{l}\text { Number of floors } \\
\text { Window design } \\
\text { Surface materials }\end{array}$ & $\begin{array}{l}0.30 \\
0.40 \\
0.55\end{array}$ & $\begin{array}{l}0.28 \\
0.37 \\
0.45\end{array}$ & $\begin{array}{l}0.27 \\
0.35 \\
0.42\end{array}$ & $\begin{array}{l}0.28 \\
0.37 \\
0.43\end{array}$ \\
\hline Structure & 0.57 & 0.55 & 0.46 & 0.53 & $\begin{array}{l}\text { Main structure } \\
\text { Roof shape }\end{array}$ & $\begin{array}{l}0.34 \\
0.23 \\
\end{array}$ & $\begin{array}{l}0.30 \\
0.25 \\
\end{array}$ & $\begin{array}{l}0.26 \\
0.19 \\
\end{array}$ & $\begin{array}{l}0.28 \\
0.25 \\
\end{array}$ \\
\hline Spatial functions & 0.44 & 0.34 & 0.29 & 0.30 & $\begin{array}{l}\text { Herding livestock } \\
\text { Daily living } \\
\text { Storage }\end{array}$ & $\begin{array}{l}0.04 \\
0.35 \\
0.05 \\
\end{array}$ & $\begin{array}{l}0.04 \\
0.27 \\
0.03 \\
\end{array}$ & $\begin{array}{l}0.04 \\
0.23 \\
0.03 \\
\end{array}$ & $\begin{array}{l}0.04 \\
0.24 \\
0.02 \\
\end{array}$ \\
\hline Ethnic culture & 0.66 & 0.54 & 0.43 & 0.48 & $\begin{array}{c}\text { Religious implements } \\
\text { Architecture decorations } \\
\text { Indoor furniture }\end{array}$ & $\begin{array}{l}0.26 \\
0.25 \\
0.15 \\
\end{array}$ & $\begin{array}{l}0.21 \\
0.24 \\
0.09 \\
\end{array}$ & $\begin{array}{l}0.16 \\
0.20 \\
0.07\end{array}$ & $\begin{array}{l}0.18 \\
0.22 \\
0.08 \\
\end{array}$ \\
\hline
\end{tabular}

traditional pitched roof, the factor of "structure" underwent the largest increase in ethnicity. "Spatial functions" had the smallest increase as the functions of herding livestock and storage were not suitable for tourism architecture. On the other hand, "daily living" displayed increased ethnicity because tourism architecture for commercial and residential purposes, such as accommodations with catering or shopping facilities, retained the chambers, prayer halls, and storage rooms of traditional Tibetan residences. There was a slight increase in the ethnicity of "appearance" and "ethnic culture," which showed that the heritage site placed more emphasis on the preservation and uniformity of the ethnic style of tourism architecture.

5.3. Analysis of the Mechanism Driving Changes in the Type of Architectural Ethnicity. Logistic regression analysis found that endogenous factors affecting the spatial changes in architectural ethnicity mainly comprised the regional altitude, slope, and distance from main transport lands and waters, and the original ethnicity type (Table 7) [53]. 

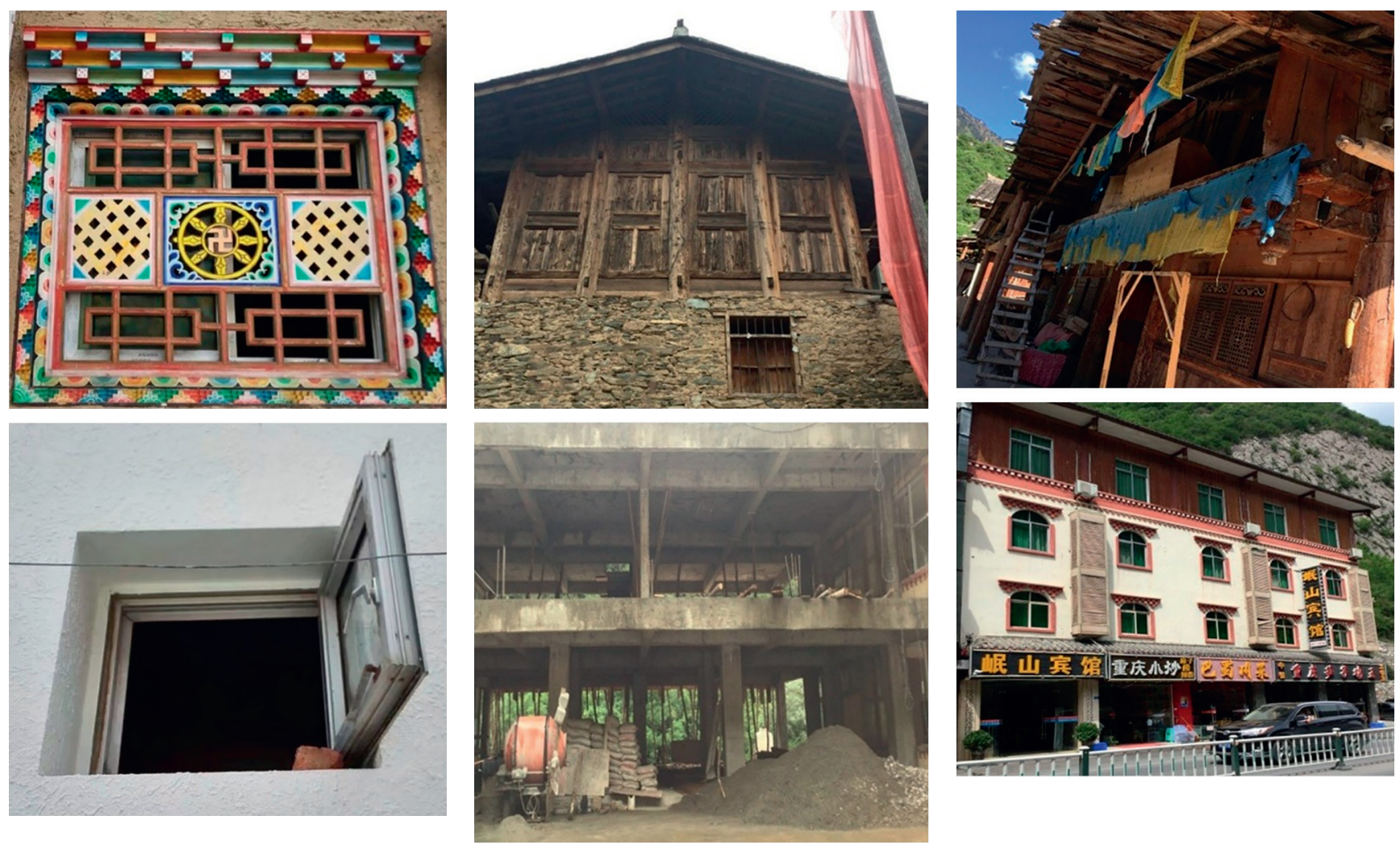

(a)

(b)

(c)
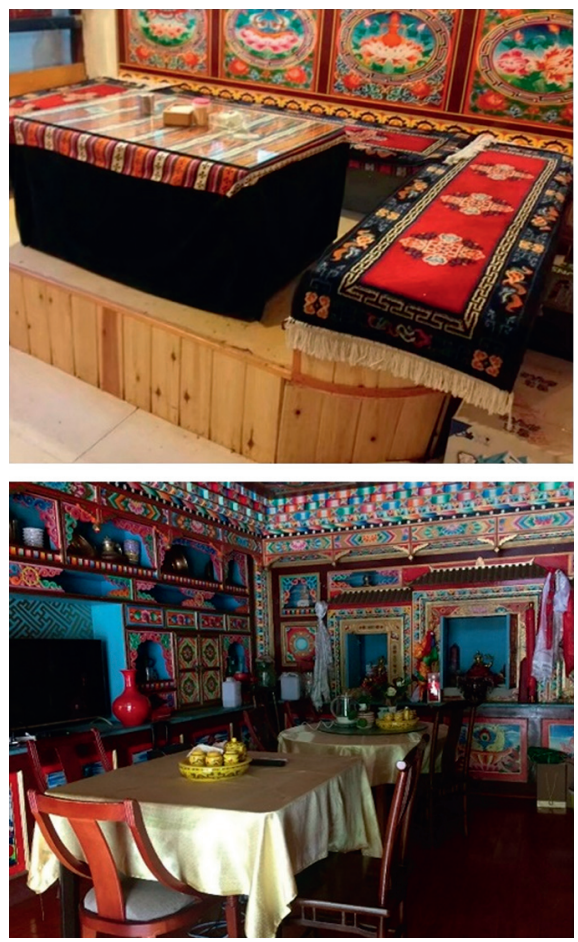

(d)

FIGURE 6: Changes in the constituent factors of architecture ethnicity for (a) window design, (b) main structure, (c) storage function, and (d) indoor furniture (source: photographed by the authors). 
TABLE 7: Relationship between spatial changes in the type of architectural ethnicity and their driving factors on the basis of results of the logistic regression analysis.

\begin{tabular}{|c|c|c|c|c|c|c|c|}
\hline \multirow[b]{2}{*}{$\begin{array}{l}\text { Ethnicity } \\
\text { type }\end{array}$} & \multicolumn{7}{|c|}{ Affecting factors } \\
\hline & Altitude & Slope & $\begin{array}{l}\text { Distance from main } \\
\text { transport lands }\end{array}$ & $\begin{array}{l}\text { Distance from } \\
\text { waters }\end{array}$ & $\begin{array}{l}\text { Distance from original } \\
\text { ethnicity type }\end{array}$ & $\begin{array}{c}\text { Constant } \\
\text { term }\end{array}$ & ROC \\
\hline Lowest & 0.0056 & -0.0496 & 0.0045 & 0.0036 & -0.0267 & -10.9860 & 0.9765 \\
\hline Lower & 0.0039 & -0.0572 & 0.0079 & -0.0034 & -0.0066 & -10.5611 & 0.9505 \\
\hline Medium & 0.0051 & 0.0037 & -0.0028 & 0.0013 & -0.0107 & -13.2186 & 0.9812 \\
\hline Higher & 0.0040 & 0.0328 & -0.0018 & 0.0021 & -0.0268 & -11.1434 & 0.9874 \\
\hline Highest & 0.0042 & 0.0608 & 0.0010 & -0.0045 & -0.0545 & -11.9351 & 0.9751 \\
\hline
\end{tabular}

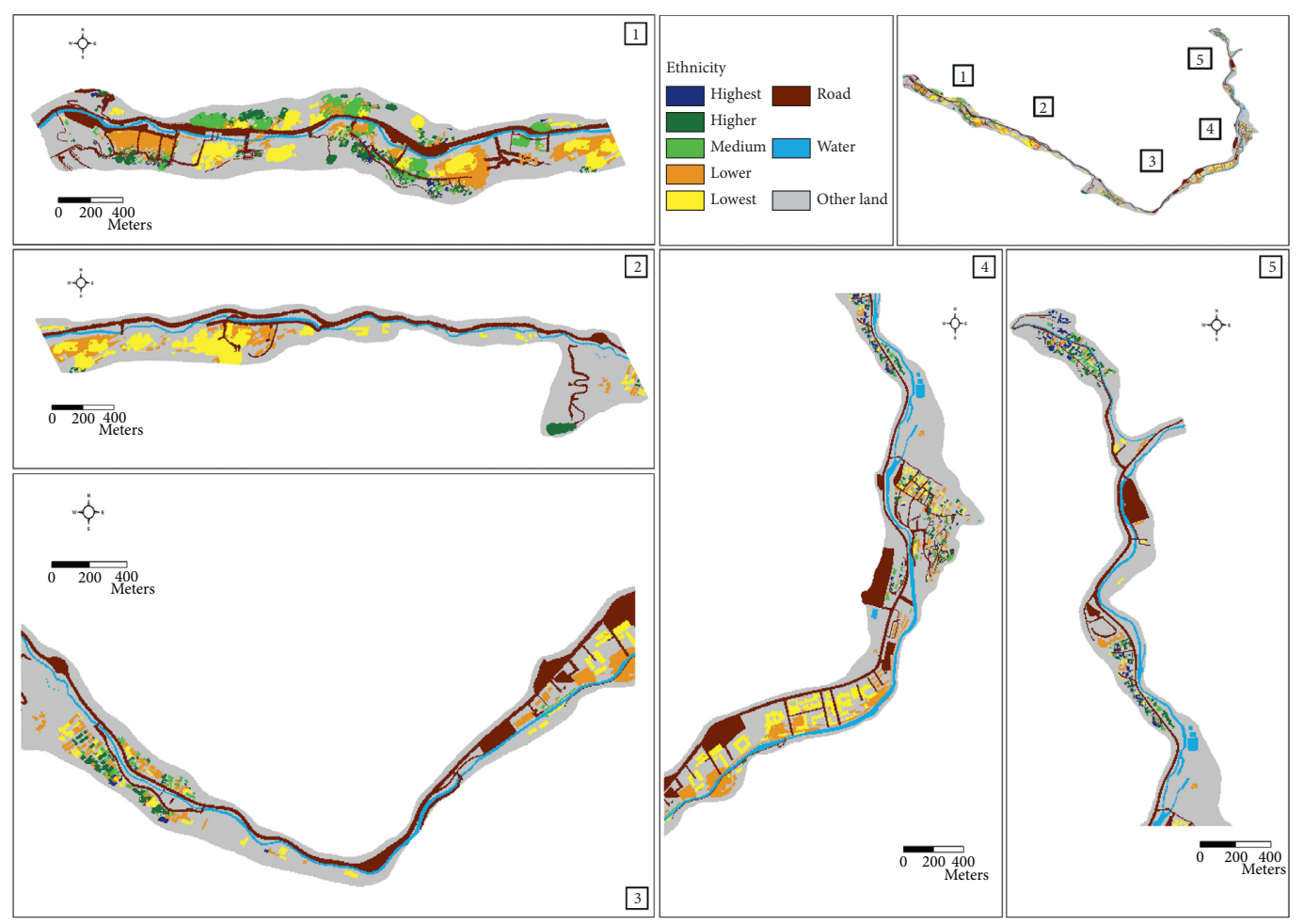

(a)

Figure 7: Continued. 


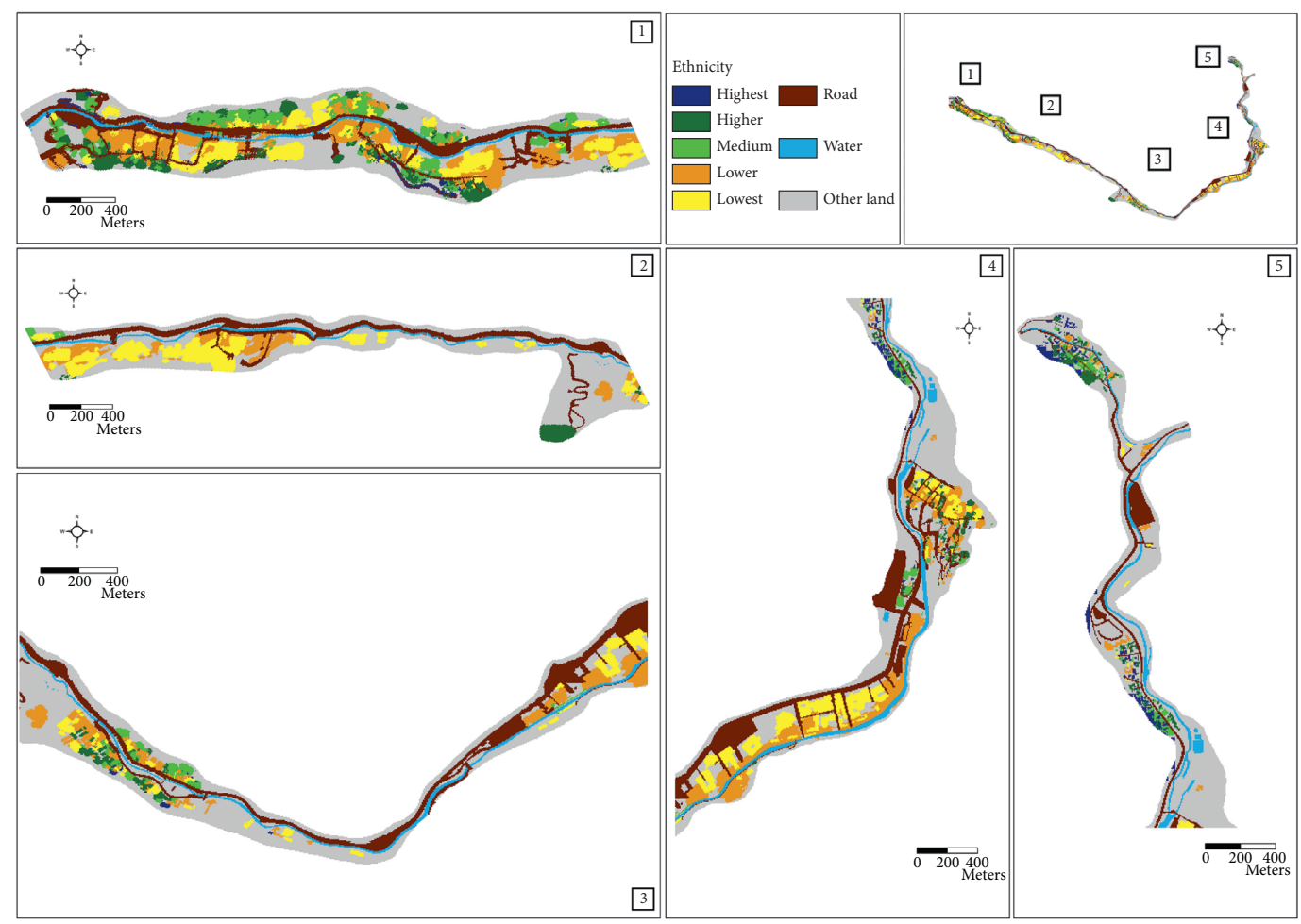

(b)

FIgURE 7: Ethnicity type distribution of architecture in Jiuzhaigou for (a) 2025 and (b) 2035.

All types of ethnicity were positively correlated with altitude; for instance, as Zhangzha Village was at a relatively high altitude, there was a greater distribution of architecture with medium ethnicity compared with other villages. On the other hand, all types of ethnicity were negatively correlated with the distance from the original ethnicity type, which implied the clumped dispersion of architecture of all ethnicity types. Slope was negatively correlated with the lowest and lower ethnicity and positively correlated with medium, higher, and the highest ethnicity; this indicated that architecture with weak ethnicity tended to spread across flat areas, while architecture of other ethnicity types was largely distributed in steeper regions. By analysing the correlation between different ethnicity types and the distance of architecture from main transport lands and waters, it was discovered that architecture with the lowest ethnicity was more likely to aggregate far away from transport systems and waters, while architecture with lower and the highest ethnicity was likely distributed further away from transport and closer to waters; finally, architecture with medium and higher ethnicity was prone to cluster around places nearby transport and distant from water.

\subsection{Spatial Change Simulation of Architectural Ethnicity from} 2025 to 2035 . To test the reliability of the Logistic-CAMarkov coupling model, this study compared the simulated distribution of architectural ethnicity of 2015 with the actual interpretation results. The Kappa score was 0.8652, which showed a high level of simulation accuracy $[54,55]$.
Prediction of the distribution of architectural ethnicity across the research region in 2025 and 2035 (Figure 7) took into account the preservation of the river ecosystem and the existing transportation system, designating the waters and transport lands as zones in which construction was restricted.

In the next 20 years, the overall architectural ethnicity of Jiuzhaigou is expected to increase, first gradually and then rapidly (Table 8). Generally speaking, the ethnicity of Jiuzhaigou will remain low and will be dominated by the lowest and lower types, which will account for more than $60 \%$ of the total ethnicity in both periods. From 2015 to 2025 , the ratio of the lowest and lower ethnicity will drop to $70.58 \%$, while the ratio of higher and the highest ethnicity will decrease to $16.11 \%$; from 2025 to 2035 , the former will decline to $68.48 \%$, while the latter will rise to $17.29 \%$ and exceed the equivalent in 2015 (16.40\%).

The regional variance of architectural ethnicity at the village level is expected to further expand. From 2025 to 2035 , the proportion of architecture with the lowest and lower ethnicity in all structures in Longkang Village will rise continuously to reach $88.44 \%$ in 2035 ; in other villages, the proportion of such architecture will display opposite trends and changes. The proportion of architecture with the highest and higher ethnicity will increase in the three villages, excluding Zhangzha Village and Longkang Village. It is worth noting that, in Pengfeng Village, the proportion of architecture with the highest ethnicity will increase from $0.00 \%$ in 2015 to $2.20 \%$ in 2035 , with clumped dispersion mainly in the central region. From 2015 to 2035, the proportion of architecture with medium ethnicity will 
TABLE 8: Composition of ethnicity type of architecture in the research region and different villages from 2025 to 2035 (sources: created by the authors on the basis of results of the Logistic-CA-Markov coupling model).

\begin{tabular}{|c|c|c|c|c|c|c|}
\hline Year & Name & Weakest (\%) & Weaker (\%) & Medium (\%) & Stronger (\%) & Strongest (\%) \\
\hline \multirow{6}{*}{2025} & Research region & 37.08 & 33.50 & 13.31 & 12.70 & 3.41 \\
\hline & Yazha Village & 8.26 & 14.64 & 17.78 & 33.68 & 25.63 \\
\hline & Congya Village & 11.11 & 24.31 & 16.50 & 23.54 & 24.53 \\
\hline & Longkang Village & 44.12 & 43.40 & 5.15 & 6.16 & 1.16 \\
\hline & Pengfeng Village & 21.20 & 30.87 & 11.00 & 33.23 & 3.69 \\
\hline & Zhangzha Village & 39.93 & 31.66 & 16.40 & 10.20 & 1.80 \\
\hline \multirow{6}{*}{2035} & Research region & 34.72 & 33.76 & 14.23 & 13.20 & 4.08 \\
\hline & Yazha Village & 4.72 & 14.22 & 17.91 & 36.72 & 26.44 \\
\hline & Congya Village & 6.18 & 16.42 & 23.03 & 17.06 & 37.31 \\
\hline & Longkang Village & 41.48 & 46.96 & 4.90 & 5.79 & 0.87 \\
\hline & Pengfeng Village & 19.45 & 32.14 & 17.52 & 28.68 & 2.20 \\
\hline & Zhangzha Village & 37.89 & 30.42 & 17.08 & 12.07 & 2.54 \\
\hline
\end{tabular}

display an upward trend in Zhangzha Village and Yazha Village, a downward trend in Longkang Village, and a downward trend followed by an upward trend in Pengfeng Village and Congya Village.

\section{Discussion and Conclusion}

6.1. Discussion. The quantitative assessment of how architectural ethnicity at world heritage sites changes in the course of tourism development and exploration of the patterns involved is of great significance to the sustainable development of these heritage sites. The basic task of top priority is to select appropriate methods for constructing a database concerning the spatiotemporal changes in architectural ethnicity. Based on high-resolution remote sensing images, this study adopted a household survey method to examine all the indices involved in the ethnicity of each structure and to compile data applicable to further analyses. Despite the time, effort, and money required to implement this process, this method can be applied widely to similar studies on the ethnicity of architecture.

Although the overall architectural ethnicity at the heritage site trended downwards, tourism architecture displayed a continuously increasing ethnicity, while the ethnicity of nontourism structures was in decline. It was evident that the tourism industry has positive impacts on the preservation of ethnicity. In terms of the spatial distribution of architectural ethnicity in the case study, villages that were closer to the entrance of the scenic area and developed earlier had lower ethnicity, whereas those that were distant from the entrance and developed later had higher ethnicity. This showed that, with the continuous development of the tourism industry, the issue of architectural ethnicity has attracted increasing public attention. The government has also implemented a series of policies to maintain the ethnicity of heritage sites, as in the standardization of architectural landscapes. Nevertheless, as regional variance may persist in the changes and trends of ethnicity, to fully understand the effects of tourism development on the ethnicity of heritage sites requires comparative research on different world heritage sites. In addition, the functions of tourism architecture can be further classified so as to analyse the characteristics of changes in the ethnicity of tourism architecture with different functions.

Using simulation to predict the future spatial distribution of architectural ethnicity can provide a useful reference for government decision-making or the management of heritage sites. For instance, the simulation results can assist policy-makers in identifying the actual regions where the architecture of various ethnicity types is distributed, while pinpointing the high-risk zones and sensitive zones with decreasing ethnicity. Policy-makers may then intervene to rectify the scale and approach of tourism development in advance, implementing effective measures to maintain and resume the architectural landscapes and, consequently, to preserve and enhance the traditional ethnicity of architecture at heritage sites. That being said, the focus of future studies should be to improve the precision of the model of spatial changes in ethnicity.

6.2. Conclusion. With the rapid development of the tourism industry at heritage sites, the architectural ethnicity of Jiuzhaigou underwent radical changes in the period 2005-2015. Overall, the architectural ethnicity at the Jiuzhaigou heritage site trended downwards and displayed an uneven spatial distribution: weak ethnicity in the west and strong in the east. It was also tightly linked with the level of tourism development in each village; the architectural ethnicity of villages varied with the distance to the entrance of the scenic area and the development time; although the ethnicity of tourism structures was weaker than that of nontourism structures, the former was on an upwards trend. In terms of the factors constituting architectural ethnicity, the decrease and increase in architectural ethnicity of the research region were mainly manifest in the respective appearance and structure of the architecture. On the other hand, the distribution of architecture with different levels of ethnicity was affected by regional altitude, slope, and the distance from main transport lands, waters, and original ethnicity type. From 2025 to 2035, the overall architectural ethnicity of Jiuzhaigou is expected to increase, first gradually and then rapidly, with increased differences among different villages. 


\section{Data Availability}

The data used to support the findings of this study are available from the corresponding author upon request.

\section{Conflicts of Interest}

The authors declare that they have no conflicts of interest.

\section{Acknowledgments}

This study was supported by the National Natural Science Foundation of China (Grant no. 41771163), Key Research and Development Project of Sichuan (no. 2018SZ0373), Sichuan Landscape and Recreation Center (JGYQ2017014), Sichuan Resource Based City Development Research Center (ZYZX-YB1707), Research Center of Sichuan County Economy Development (xy2018011), and Southwestern Poverty Reduction and Development Research Center (SCP1815).

\section{References}

[1] J. Nunta and S. Sukolratanametee, "The impact of urbanization on the physical environment of Lamphun's cultural landscape," Nihon Hoshasen Gijutsu Gakkai Zasshi, vol. 29, pp. 565-572, 2006.

[2] K. Gwendolyn, "The impact of urban sprawl on cultural heritage in Herat, Afghanistan: a GIS analysis," Digital Applications in Archaeology and Cultural Heritage, vol. 11, Article ID e00086, 2018.

[3] F. Wang, L. I. Wei, and P. Martin, "The new conflicts, strategies and explorations of urbanization and locality: overview on the Sino-German symposium," Geographical Research, vol. 33, pp. 2205-2214, 2004.

[4] J. Yang, Y. C. Wang, X. M. Xiao, C. Jin, J. H. Xia, and X. M. Li, "Spatial differentiation of urban wind and thermal environment in different grid sizes," Urban Climate, vol. 28, 2019.

[5] Z. Qiao, L. Liu, Y. Qin, X. Xu, B. Wang, and Z. Liu, "The impact of urban renewal on land surface temperature changes: a case study in the main city of Guangzhou, China," Remote Sensing, vol. 12, no. 5, p. 794, 2020.

[6] C. He, T. Chen, X. Mao, and Y. Zhou, "Economic transition, urbanization and population redistribution in China," Habitat International, vol. 51, pp. 39-47, 2016.

[7] Y. Li, L. Jia, W. Wu, J. Yan, and Y. Liu, "Urbanization for rural sustainability-rethinking China's urbanization strategy," Journal of Cleaner Production, vol. 178, pp. 580-586, 2018.

[8] K. Kiruthigan and K. Thirumaran, "Effects of urbanization on historical heritage buildings in Kumbakonam, Tamilnadu, India," Frontiers of Architectural Research, vol. 8, no. 1, pp. 94-105, 2018.

[9] Z. F. Huang, L. Lu, Q. Su et al., "Research and development of rural tourism under the background of new urbanization: theoretical reflection and breakthrough of predicament," Geographical Research, vol. 34, pp. 1409-1421, 2015.

[10] L. Zhao and Y. Dong, "Tourism agglomeration and urbanization: empirical evidence from China," Asia Pacific Journal of Tourism Research, vol. 22, no. 5, pp. 512-523, 2017.

[11] I. D. Putra, The impact of tourism on the transformation of the traditional Balinese house, Ph.D. thesis, Deakin University, Victoria, Australia, 2015.
[12] S. Jin, J. Yang, E. Wang, and J. Liu, "The influence of highspeed rail on ice-snow tourism in northeastern China," Tourism Management, vol. 78, p. 104070, 2020.

[13] H. W. Kierchhoff, "Architecture and tourism," Annals of Tourism Research, vol. 24, no. 1, pp. 249-251, 1997.

[14] T. Avermaete, "Architecture and tourism in Italian Colonial Libya: an ambivalent modernism," Journal of Design History, vol. 20 , no. 4 , pp. $262-265,2006$.

[15] L. Martha and A. Kotsaki, "Ancient Greek drama and its architecture as a means to reinforce tourism in Greece," Procedia-Social and Behavioral Sciences, vol. 148, pp. 573578, 2014.

[16] S. K. Winkler, "Architecture \& tourism: an exciting synthesis of opportunities for future tourism development," Acta Turistica Nova, vol. 2, pp. 269-274, 2008.

[17] A. Besculides, M. E. Lee, and P. J. Mccormick, "Residents' perceptions of the cultural benefits of tourism," Annals of Tourism Research, vol. 29, no. 2, pp. 303-319, 2002.

[18] J. G. Brida, L. Osti, and M. Faccioli, “Residents' perception and attitudes towards tourism impacts: a case study of the small rural community of Folgaria (Trentino-Italy)," Benchmarking: An International Journal, vol. 18, no. 3, pp. 359-385, 2011.

[19] G. Tiberghien, H. Bremner, and S. Milne, "Performance and visitors' perception of authenticity in eco-cultural tourism," Tourism Geographies, vol. 19, no. 2, pp. 287-300, 2017.

[20] L. Yang, “Tourists' perceptions of ethnic tourism in Lugu Lake, Yunnan, China," Journal of Heritage Tourism, vol. 7, no. 1, pp. 59-81, 2012.

[21] H. Zamani-Farahani and G. Musa, "The relationship between Islamic religiosity and residents' perceptions of socio-cultural impacts of tourism in Iran: case studies of Sare'in and Masooleh," Tourism Management, vol. 33, no. 4, pp. 802-814, 2012.

[22] R. Pontius, "Quantification error versus location error in comparison of categorical maps," Photogrammetric Engineering and Remote Sensing, vol. 66, pp. 1011-1016, 2000.

[23] A. M. A. Franco, J. C. Brito, and J. Almeida, "Modelling habitat selection of common cranes Grus grus wintering in Portugal using multiple logistic regression," Ibis, vol. 142, no. 3, pp. 351-358, 2008.

[24] A. Siddiqui, A. Siddiqui, S. Maithani, A. K. Jha, P. Kumar, and S. K. Srivastav, "Urban growth dynamics of an Indian metropolitan using CA Markov and logistic regression," The Egyptian Journal of Remote Sensing and Space Science, vol. 21, no. 3, pp. 229-236, 2018.

[25] L. Su, J. H. Zhu, S. H. Ren et al., "Landscape pattern change prediction of Jinhu coastal area based on Logistic-CA-Markov model," Advances in Information Sciences and Service Sciences, vol. 4, pp. 1-10, 2012.

[26] X.-Q. Zheng, L. Zhao, W.-N. Xiang, N. Li, L.-N. Lv, and $\mathrm{X}$. Yang, "A coupled model for simulating spatio-temporal dynamics of land-use change: a case study in Changqing, Jinan, China," Landscape and Urban Planning, vol. 106, no. 1, pp. 51-61, 2012.

[27] J. Yang, W. L. Liu, Y. H. Li, X. M. Li, and Q. S. Ge, "Simulating intraurban land use dynamics under multiple scenarios based on fuzzy cellular automata: a case study of Jinzhou district, Dalian," Complexity, vol. 2018, Article ID 7202985, 17 pages, 2018.

[28] H. Memarian, S. Kumar Balasundram, J. Bin Talib, C. Teh Boon Sung, A. Mohd Sood, and K. Abbaspour, "Validation of CA-markov for simulation of land use and cover change in the 
Langat basin, Malaysia," Journal of Geographic Information System, vol. 4, no. 6, pp. 542-554, 2012.

[29] P. Subedi, K. Subedi, and B. Thapa, "Application of a hybrid cellular automaton-Markov (CA-Markov) model in landuse change prediction: a case study of saddle creek drainage basin, Florida," Applied Ecology and Environmental Sciences, vol. 1, no. 6, pp. 126-132, 2013.

[30] D. He, J. Zhou, W. Gao et al., "An integrated CA-markov model for dynamic simulation of land use change in Lake Dianchi watershed," Acta Scientiarum Naturalium Universitatis Pekinensis, vol. 50, pp. 1095-1105, 2014.

[31] D. Guan, H. Li, T. Inohae, W. Su, T. Nagaie, and K. Hokao, "Modeling urban land use change by the integration of cellular automaton and Markov model," Ecological Modelling, vol. 222, no. 20-22, pp. 3761-3772, 2011.

[32] G. D. Jenerette and J. Wu, "Analysis and simulation of landuse change in the central Arizona-Phoenix region, USA," Landscape Ecology, vol. 16, no. 7, pp. 611-626, 2001.

[33] H. Wail, "Historical and cultural landscape of the ancient villages of northern Syria," European Science Review, no. 5-6, pp. 3-6, 2015.

[34] P. Liu, C. Liu, Y. Deng et al., "Landscape division of traditional settlement and effect elements of landscape gene in China," Acta Geographica Sinica, vol. 65, pp. 1496-1506, 2010.

[35] X. Y. Shen, P. L. Liu, Y. Y. Deng, and L. J. Wang, "Landscape communities of traditional settlement in southern China and their values of conservation and utilization," Geographical Research, vol. 25, pp. 485-494, 2006.

[36] F. G. S. Giucastro and D. Giordano, "Et(h)nic architecture in mediterranean area," Energy Procedia, vol. 96, pp. 868-880, 2016.

[37] W. Feng and M. Zhang, "Landscape information identification of traditional residence in mountainous region: a case study of Longtang village in Chongqing Jiangjin district," Journal of Chongqing Normal University, vol. 34, pp. 120-126, 2017.

[38] A. Ghaffarianhoseini, U. Berardi, N. D. Dahlan, and A. Ghaffarianhoseini, "What can we learn from Malay vernacular houses?" Sustainable Cities and Society, vol. 13, pp. 157-170, 2014.

[39] H. X. Wang, "Analysis on the decoration culture of residential buildings in southwest ethnic minority areas," Guizhou Ethnic Studies, vol. 35, pp. 132-136, 2014.

[40] P. Bo and L. R. C. C. O. J. County, Local Records of Jiuzhaigou County: 1986-2005, China Local Records Publishing, Beijing, China, 2011.

[41] G. Guo, "Study on the adaptability of traditional settlement and dwellings in ando tibetan area of aba prefecture," Master thesis, Southwest Jiaotong University, Chengdu, China, 2016.

[42] J. Liu and W. Zhuang, "Comparative study on traditional and new vernacular dwelling of Tibetan village in Jiuzhai valley national park," HuaZhong Architecture, vol. 34, pp. 168-171, 2016.

[43] J. Yang, Architectural Culture in Tibetan Areas of Sichuan, Sichuan Ethnic Publishing House, Chengdu, China, 2007.

[44] Q. Ye, Sichuan Tibetan Residence, Sichuan Ethnic Publishing House, Chengdu, China, 1989.

[45] K. M. A.-S. Al-Harbi, "Application of the AHP in project management," International Journal of Project Management, vol. 19, no. 1, pp. 19-27, 2001.

[46] V. Wickramasinghe and S. E. Takano, "Application of combined swot and analytic hierarchy process (AHP) for tourism revival strategic marketing planning: a case of Sri Lanka tourism: a case of Sri Lanka tourism," Journal of the
Eastern Asia Society for Transportation Studies, vol. 8, pp. 954-969, 2010.

[47] J. Zhang and Z. Pang, "Model construction and empirical analysis of the suitability evaluation of urban river tourism development," Economic Geography, vol. 37, pp. 209-215, 2017.

[48] Y. W. Yong, K. A. Keng, and T. L. Leng, "A delphi forecast for the Singapore tourism industry: future scenario and marketing implications," International Marketing Review, vol. 23, pp. 15-26, 1989.

[49] T. L. Saaty, "A scaling method for priorities in hierarchical structures," Journal of Mathematical Psychology, vol. 15, pp. 234-281, 1997.

[50] R. Gil Pontius and L. C. Schneider, "Land-cover change model validation by an ROC method for the Ipswich watershed, Massachusetts, USA," Agriculture, Ecosystems and Environment, vol. 85, no. 1-3, pp. 239-248, 2001.

[51] C. H. Zhou, Z. L. Sun, and Y. C. Xie, Geographic Cellular Automata Study, Science Press, Beijing, China, 1999.

[52] X. I. Jianchao, M. Zhao, and G. E. Guansheng, "The microscale analysis of rural settlement land use pattern: a case study of Gouge village of Yesanpo scenic area in Hebei province," Acta Geographica Sinica, vol. 66, no. 12, pp. 1707-1717, 2011.

[53] Z. Qiao, C. Wu, D. Zhao et al., "Determining the boundary and probability of surface urban heat island footprint based on a logistic model," Remote Sensing, vol. 11, no. 11, p. 1368, 2019.

[54] J. Cohen, "A coefficient of agreement for nominal scales," Educational and Psychological Measurement, vol. 20, no. 1, pp. 37-46, 1960.

[55] Z. Jie, Y. K. Zhou, R. Q. Li et al., “Accuracy assessments and uncertainty analysis of spatially explicit modeling for land use/cover change and urbanization: a case in Beijing metropolitan area," Science China (Earth Sciences), vol. 53, pp. $173-180,2010$. 